\title{
1. Introduction: the climate change problem and solutions
}

This book examines what justice requires of current generations in addressing climate change to safeguard the welfare of future generations and how such obligations should be reflected in international law. The first part of this question is addressed by identifying several essential criteria for ensuring intergenerational justice in relation to climate change. These criteria - or justice principles - provide a basis for critically assessing the existing international law regime for climate change. They also provide a springboard for reforming contemporary international climate change law.

The challenge of addressing anthropogenic climate change raises intergenerational equity or justice ${ }^{1}$ issues. Future generations who did not cause climate change will be the most severely impacted. This applies not only to individual or generations' contributions to creating the problem, but also in relation to nation states. The most graphic example is that the small island states of Kiribati and Tuvalu, with negligible contribution to global greenhouse gas emissions (GHG), will be amongst the nations most severely affected, with the land mass of these Pacific island states becoming uninhabitable because of salt water intrusion and ultimately because they are completely submerged in the coming century. ${ }^{2}$

Climate change also raises issues of intragenerational justice in terms of which states and societies should bear the costs of mitigating climate change by reducing (GHG) emissions. The preponderance of scientific evidence indicates that we need a total decarbonisation of the global economy by 2050 - the elimination of GHG emissions from human activities - to have a reasonable chance of avoiding dangerous anthropogenic climate change (see 1.4 below). But we are currently locked into fossil-fuel-dependent economic development. To achieve these emission reductions it is apparent that substantial cuts in GHG emissions will be needed, by both industrialised countries and also at least the larger developing countries (Gupta et al. 2007: 751). ${ }^{3}$ However, developing countries ${ }^{4}$ have resisted binding targets in the UN negotiations, arguing that the industrialised countries created the problem through their historic emissions and that only when industrialised countries have made deep 
cuts will developing countries take action. Developing countries have been emphasising justice towards current generations as being of paramount importance, with a strong emphasis on the need to address poverty now (Scholtz 2009: 167). ${ }^{5}$ Industrialised countries have emphasised in their rhetoric the need to take action now for the benefit of future generations (Scholtz 2009: 170) although to date most have done relatively little in terms of curbing GHG emissions (UNFCCC 2012). The international negotiations on climate change may accordingly be characterised as both a conflict between justice and effectiveness, ${ }^{6}$ and a conflict between intergenerational equity and intragenerational equity.

Curiously, while there is a wealth of literature by philosophers and public policy experts on intergenerational justice, there is very little by international legal scholars. ${ }^{7}$ This is despite the fact that there are strong interconnections between philosophical models of intergenerational equity and international law formulations of the same concept. A central argument in this book is that some of the philosophers' insights in relation to ethics and justice are of great value in analysing the international law principle of intergenerational equity. As Koskenniemi (2005) has argued, international law performs a dual function in justifying state action but also as a basis for critiquing state action through its incorporation of ethical principles. We shall see this dual function is very much in evidence when we explore the ethical principles relating to intergenerational justice and their - albeit weak - incorporation in international law rules. Before examining the justice and international law dimensions of these issues, it is essential to have an understanding of the salient aspects of climate change science.

This chapter sets out the key elements of climate change science (1.1), including the notions of abrupt climate change and tipping points (1.1.2). This leads to a discussion of climate change impacts (1.1.3), including the key concepts of risk and uncertainty (1.1.4). The global mitigation response required to address the climate change challenge is addressed with a focus on what is known as a 'budget' approach which identifies the volume of carbon that can safely be stored in the atmosphere before it causes dangerous climate change (1.2). The discussion then moves to the justice and ethics issues raised by the science (1.3), with the distinction drawn between intragenerational and historic justice (1.4) and intergenerational justice (1.5). Procedural justice issues are addressed (1.6) before moving on to discuss the notion of 'discounting' employed by economists (1.8). The focus on international law in this book is explained (1.9) in the context of the current climate change negotiations and the existing UN climate change regime (1.10). Conclusions are drawn in 1.11 . 


\subsection{CLIMATE CHANGE SCIENCE}

Climate change refers to "change in the average pattern of weather over a long period "typically decades or longer" (Australian Academy of Science 2010: 4). The basic processes of climate change are well understood. Since the late nineteenth century it was known that increases of carbon dioxide $\left(\mathrm{CO}_{2}\right)$ into the atmosphere 'would act like added insulation in the earth's atmosphere, trapping more heat near the surface' (Australian Academy of Science 2010: 10). GHG emissions play a key role in determining climate and bringing about climate change. 'Greenhouse gases include water vapour, carbon dioxide $\left(\mathrm{CO}_{2}\right)$, methane, nitrous oxide and industrial gases such as chlorofluorocarbons (CFCs)' (Australian Academy of Science 2010: 4). These gases function as an 'insulating blanket', maintaining the earth's surface temperature (Australian Academy of Science 2010: 4). However, with the exception of water vapour, the concentrations of all of these gases in the atmosphere are being influenced by human activities. Concentrations of these gases, particularly $\mathrm{CO}_{2}$, have increased dramatically since the Industrial Revolution, particularly as a result of fossil-fuel-burning and other industrial processes including cement production, but also from deforestation linked to agriculture (Australian Academy of Science 2010: 10). Increasing population has been an integral aspect of this process and will continue to be so into the future (IPCC 2007a: 18).

A particular feature of $\mathrm{CO}_{2}$ - the most important GHG - is vital in terms of the intergenerational issues considered in this book. This is the persistence of $\mathrm{CO}_{2}$ in the atmosphere. Scientists have now discovered that, unlike trace gases with well-defined timelines, $\mathrm{CO}_{2}$ persists in the atmosphere for a lengthy period of time. The impact of this physical property of $\mathrm{CO}_{2}$ is dramatic:

Stabilization of $\mathrm{CO}_{2}$ emissions at current levels will result in a continuous increase of atmospheric $\mathrm{CO}_{2}$ over the 21 st century and beyond ... In fact, only in the case of essentially complete elimination of emissions can the atmospheric concentration of $\mathrm{CO}_{2}$ ultimately be stabilized at a constant level (Meehl et al. 2007: 824-5).

Put differently, even if today human beings ceased activities causing GHG emissions entirely, concentrations of $\mathrm{CO}_{2}$ in the atmosphere would continue with only a reduced rate of growth over the coming decades (Meehl et al. 2007: 824-5).

Climate change science became known to a wider audience in 1988 when the Intergovernmental Panel on Climate Change (IPCC) was 
created by the United Nations Environment Programme (UNEP) and the World Meterological Organization (WMO). The IPCC was tasked to assess in an 'objective, open and transparent' way the scientific, technical and socio-economic information relevant to understanding humaninduced climate change while remaining 'neutral with respect to policy' (IPCC 2006: para 2). The IPCC carries out this assessment by bringing together scientists from around the world and seeking to reach agreement on various aspects of climate change, from the physical causes and impacts to mitigation and adaptation issues (IPCC 2006: para 2).

The most recent report of the IPCC is the Fourth Assessment Report, released in 2007 (IPCC 2007a), which was 'written by more than 450 lead authors, 800 contributing authors and reviewed by over 2,500 expert and government reviewers', with many of the lead authors considered the world's top experts in their field (Anderegg and Harold 2009: 7). The IPCC assessment reports can reasonably be interpreted as the state of the mainstream science on climate change (Anderegg and Harold 2009: 4). Steffen (2009: 4) points out that anthropogenic emissions of $\mathrm{CO}_{2}$ have been 'rising at or near the upper limit of the envelope of the IPCC projections since they were first published in 1990'. While 'considerable uncertainty' remains in relation to estimates of future sea-level rise, empirical observations have confirmed that actual levels of sea-level rise have been occurring 'toward the upper range of the IPCC projections' (Steffen 2009: 11).

The Fourth Assessment Report of the IPCC concluded with 'very high confidence' - defined as more than 90 per cent likelihood - that 'the net effect of human activity since 1750 has been one of warming' (IPCC 2007a: section 1). It went on to conclude that 'most of the observed increase in global average temperatures since the mid 20th century is very likely due to the observed GHG concentrations' (IPCC 2007a: section 1). The Report concluded that fossil fuel emissions were the most significant source of GHG emissions with agriculture-related emissions also highly significant. Since the IPCC Fourth Assessment Report, the assessment of attribution has been further strengthened in the scientific literature (Stott et al. 2010). ${ }^{8}$

The IPCC Fourth Assessment Report has used a range of models to make projections as to global average surface warming into the future based on a range of assumptions relating to technological change and economic and population growth. These projections are in the range of $1.1-6.4^{\circ} \mathrm{C}$ (with the best estimate of $1.8-4^{\circ} \mathrm{C}$ ) by the end of the twenty-first century (IPCC 2007b: 13).

There is overwhelming support amongst the mainstream - peerreviewed - scientific community in relation to the key aspects of climate 
change science. This is confirmed by reports of numerous national academies of science (Garnaut 2011: 47). If a consensus is defined as more than 95 per cent agreement, surveys of climate scientists' peerreviewed research outputs have concluded that there is a consensus (around 97 per cent) agreement in relation to the key propositions. These propositions are that global average temperature has increased since the preindustrial times and that anthropogenic GHG emissions are a significant contributing factor in these temperature increases (Anderegg and Harold 2009: 15). ${ }^{9}$ However, significant uncertainty remains as to the rate and regional distribution of climate change impacts, including for example changes in rainfall distribution (Stott et al. 2010).

A small minority of scientists continue to call into question the mainstream science, but a substantial number of these are not qualified scientists or have geology - not climate science - qualifications (Anderegg 2010: 31). The views of those who challenge the mainstream science - 'deniers', often mislabelled as 'sceptics' (all scientists are sceptics) - have gained widespread publicity, partly owing to deliberate misinformation campaigns by powerful vested interests (this is explored in Chapter 6). This book takes as its starting point the mainstream science.

\subsubsection{Abrupt Climate Change and Tipping Points}

Projections of future climate change impacts have involved a gradualist paradigm according to which climate change outcomes are largely an extension of projections based on current processes. In addition, more attention is gradually focusing on an abrupt paradigm involving the crossing of particular thresholds with catastrophic impacts (Gardiner 2009: 141-2). The abrupt paradigm is linked to so-called 'tipping points'. A tipping point is a critical threshold at which the future state of a system can be qualitatively altered by a small change (Lenton et al. 2008). Abrupt climate change refers to tipping point change 'which occurs faster than its cause' (Allison et al. 2009: 40).

The most well-known potential tipping points include the melting of the Greenland ice sheet, and the West Antarctic ice sheet, both with the potential for 'large and global sea level rise' (Lenton et al. 2008, Kriegler et al. 2009). A further tipping point relates to dieback of the Amazon rainforest, where it has been suggested that there is a $2^{\circ} \mathrm{C}$ temperature increase threshold. 'Beyond this threshold the area of dieback rises rapidly from over 20 to 60 percent' (Jones and Lowe 2011). ${ }^{10}$

Kriegler et al. (2009) have conducted a survey of 43 experts to seek to gain a better understanding of the probabilities of various tipping points 
occurring. The conclusion of this study was that while there was large uncertainty among experts about the prospects of triggering major changes in the climate system, this did not imply that the probability of such outcomes was remote (Kriegler et al. 2009: 7). In fact, the study found that the experts allocated 'significant probability' to some tipping point events, such as the dieback of the Amazon rainforest and melting of the Greenland ice sheet (Kriegler et al. 2009: 1).

\subsubsection{Impacts}

Certain climate change impacts predicted by the IPCC will particularly impact on future generations. Impacts predicted by the IPCC to be likely or very likely include the following:

- rising sea levels

- human health impacts including increases in mortality as a result of increased frequency of extreme weather events, including floods, storms and heatwaves

- the increased transmission area of various disease agents

- increased droughts

- increased extinction of various species

- the permanent acidification of the oceans (IPCC 2007c: 9-13).

A number of these impacts are permanent and irreversible, for example species extinctions and ocean acidification. Moreover, some research since 2007 indicates that there may be a risk that aspects of the climate system enter into a state from which they cannot return (for example Jones and Lowe 2011). ${ }^{11}$

Impacts generally are predicted to be more severe for developing countries, particularly those in Africa and the "Asian and African mega-deltas, due to large populations and high exposure to sea level rise, storm surges and river flooding' (IPCC 2007a: section 3.3.3). It is also important to recognise that there will be significant differences between the impacts of climate change within developing countries, with 'the poor, elderly and very young particularly impacted' (IPCC 2007a: section 3.3.3).

According to the most recent predictions, a number of the impacts sketched above will already be in evidence by 2020, impacting the lives of younger people alive today. For example, while the impact of climate change on water resources across the African continent is uneven, on some assessments the population 'at risk of increased water stress in Africa ... is projected to be $75-250$ million ... by the 2020 s' with 
reduced agricultural production and consequent impacts on poverty and food security (IPCC 2008: 81).

Edward Page (2006: 36) points out that ' $[\mathrm{t}]$ he most vulnerable of all to climate change impacts will be future members of developing countries', and that the greatest inequalities in terms of climate change impacts will be between the current elites in industrialised countries and the future poorest members of developing countries. Further into the future, however, it remains less clear whether industrialised countries maintain their current status.

In conclusion, we can say that the mainstream view among scientists is that without deep GHG emission cuts there is a high likelihood of severe impacts resulting from climate change. We can also say that without deep GHG emission cuts there is a substantial risk of abrupt climate change involving catastrophic impacts.

\subsubsection{Risk and Uncertainty}

The propositions set out in the previous paragraph included the notions of 'likelihood' and 'risk'. Uncertainty is important in considering intergenerational justice and climate change for a number of reasons. Firstly, some have argued that the fact that scientists cannot predict with accuracy climate change impacts, for example at the regional level, is a justification for not taking mitigation action. According to this approach, mitigation action will definitely cause economic harm now, and this is not outweighed by future uncertain benefits of mitigation. This approach, however, is unconvincing and contravenes the precautionary principle, the essence of which is that it is unjustifiable to wait for further certainty in the science if the environmental harm involved is irreversible (see below 3.4.2). Moreover, we have seen that scientists predict a highly likely range of severe impacts from climate change and a serious possibility of catastrophic harm. The fact that there is a range of possible impacts does not undermine the need for action to mitigate climate change. Consider the following hypothetical scenario. Scientific studies indicate that the release of highly toxic material into a river would very likely cause between 20 and 80 human deaths in a downstream village. The fact that in this scenario there is a range of likely harm does not justify breaching the causal chain of ethical responsibility and we would likely all agree that the release of the toxic material should not occur. ${ }^{12}$

The argument presented above for not taking mitigation action is often linked to a claim that one should wait until there is more certainty in the science, and in the meantime increase scientific research funding. This approach is also problematic. If we consider our hypothetical river 
scenario above, it would not make sense to allow the toxic material to be released in the river pending better scientific data on the likely number of deaths. There is a strong analogy between this scenario and tipping points. In relation to the latter, scientists maintain that if we wait until we have more precise information on the thresholds involved, it will be too late and that therefore early preventive action in reducing GHG emissions is a better option (Allison et al. 2009: 7). It is also important to bear in mind that uncertainty also arises from economic, social and other factors which are built into the models and are important in terms of predicting future emissions (Jamieson 1992). ${ }^{13}$

The argument that climate science is too uncertain to serve as a basis for mitigation is also based on a misconception about scientific method. The assumption is sometimes made that science can deliver absolute (100 per cent) certainty in causal relationships. Scientific method does not operate in this manner. Rather, science deals with working hypotheses that are tested in relation to empirical data with all claims 'potentially open to revision' (Peel 2005: 35). The climate models upon which much climate change science is based have been tested against observations in relation to actual changes in climate change and found to be highly reliable (IPCC 2007b: ch8-9). As outlined above, the key processes in climate change science are known with a high degree of certainty. The evidence is with greater than 90 per cent certainty that human activities have been causing increased global warming from GHG emissions. There is a less than 50 per cent likelihood that the observed increase in global temperature over the last 50 years is occurring owing to factors other than anthropological GHGs (IPCC 2007b: ch9, p665). The idea that science can deliver 100 per cent certainty is based on an 'illusive fiction' (Peel 2005: 35).

Climate change policy involves policy-making in relation to risk of harm, and in this sense is no different from any other environmental policy areas. Science - with its in-built uncertainty - can only present information about likely risks, it cannot prescribe policy responses. Ultimately, policy decisions about what level of climate-change-related risks is acceptable is a question of societal values (Peel 2005: 151).

\subsection{GLOBAL MITIGATION REQUIRED: A BUDGET APPROACH}

Values are reflected in the defining of a global mitigation objective informed by sound science. The defining of such an objective, which is crucial for delivering intergenerational justice, is vital. 
The United Nations Framework Convention on Climate Change (UNFCCC) defines its objective as 'stabilization of GHG concentrations in the atmosphere at a level that would prevent dangerous anthropogenic interference with the climate system' (Article 2). The UNFCCC does not define the point at which 'dangerous anthropocentric interference' might occur, and defining such a threshold is inevitably a policy issue necessarily involving value assumptions (Oppenheimer and Petsonk 2005). Since 2008 a number of international instruments have accepted the requirement of keeping the global mean temperature increase below $2^{\circ} \mathrm{C}$ (for example Copenhagen Accord). ${ }^{14}$ However, scientists have been suggesting that 'the current temperature increase compared to preindustrial levels $\left(\sim 0.8^{\circ} \mathrm{C}\right)$ is already sufficient to increase the likelihood of severe and damaging events occurring' (Min et al. 2011) ${ }^{15}$ It is clear that even if emissions were to be kept under $2^{\circ} \mathrm{C}$, this would involve considerable harm. For example, with a global temperature rise of $2^{\circ} \mathrm{C}$, the area flooded in Bangladesh is projected to increase by 'at least 23-29\%' (IPCC 2008: 41).

The IPCC in its Fourth Assessment Report indicated that a 10-40 per cent reduction in global GHG emissions by 2020 below 1990 levels and a 40-95 per cent reduction by 2050 as against 1990 levels was required in order to have about a 50 per cent chance of limiting temperature increases to $2^{\circ} \mathrm{C}$ above preindustrial levels (IPCC 2007d: 748). More recently scientists have been concluding that a total decarbonisation of the global economy is required to keep global warming below $2^{\circ} \mathrm{C}$. For example, Allison et al. (2009: 7) conclude that if climate change is to be limited to a maximum of $2^{\circ} \mathrm{C}$ above preindustrial levels, global GHG emissions need to "peak between 2015 and 2020 and then decline rapidly'. Moreover, to stabilise global climate 'a decarbonized global society - with near zero emissions of $\mathrm{CO}_{2}$ and other long-lived GHGs needs to be reached well within this century ... with average annual per capita emissions ... well under one metric tonne $\mathrm{CO}_{2}$ by 2050', which amounts to a 80-95 per cent reduction in per capita emissions in developed nations compared with emission levels in 2000 (Allison et al. 2009: 7).

The notion of moving to a decarbonised economy entails 'emission budgets'. Put simply, the idea is that GHG emissions are akin to a limited 'resource'. Between now and the time at which the global economy is decarbonised, this 'resource' must be fairly allocated within an overall cap or 'budget'. The link between emissions and carbon concentrations in the atmosphere is analogous to water filling a bathtub: to avoid the bathtub overflowing - exceeding the 'budget' - it is essential to turn off 
the tap, preferably gradually or this must be done abruptly at the last moment (Saul et al. 2012: 63).

Meinshausen et al. (2009) have analysed GHG emission budgets for the 2000-50 period that would limit warming throughout the twenty-first century to below $2^{\circ} \mathrm{C}$. This research builds on the Fourth IPCC Assessment Report and more recent research (Meinshausen et al. 2009: 1158). Their research concluded that for there to be even a 50 per cent chance of staying within a global warming target of $2^{\circ} \mathrm{C}$, cumulative emissions from fossil sources and land-use change must be kept within 1000 gigatons (Gt) $\mathrm{CO}_{2}$ over the period 2000-49. (Meinshausen et al. 2009: 1159). A similar conclusion is reached by Allen et al. (2009a: 1163-6), who conclude that even considering $\mathrm{CO}_{2}$ alone, cumulative emissions of carbon must not surpass 1 trillion tonnes. They point out that it has taken the last 250 years to burn the first half trillion tonnes of carbon, but on current trends the next half trillion tonnes of carbon will be burned in less than 40 years (Allen et al. 2009b: 57). ${ }^{16}$

The idea of a carbon budget of 1 trillion tonnes is helpful as a 'shorthand' for a climate change mitigation objective (Shue 2011: 302). However, it must be recognised that this particular budget may need to be modified given the increasing likelihood that a $2^{\circ} \mathrm{C}$ rise in global mean temperature becomes unattainable (UNEP 2011), forcing a shift to, for example, a $3^{\circ} \mathrm{C}$ target. A further possibility is that changes in the science require a tighter emissions budget, bearing in mind the role that values play in deciding upon a particular emissions target (Shue 2011: 302). ${ }^{17}$ In spite of these factors, the underlying logic of an emissions budget remains valid.

The enormity of the challenge of staying within this cumulative budget is evident when one considers that the International Energy Agency (IEA) predicts a global increase in energy demand of one-third to 2035, with fossil fuels remaining dominant in the energy mix, in spite of an increase in renewable energy forms and natural gas (IEA 2012: 1). Global GHG emissions must peak soon; as the risk of exceeding $2^{\circ} \mathrm{C}$ increases, the later the peak in emissions occurs (Meinshausen et al. 2009: 1158).

How does a budget approach translate to mitigation targets? There is a range of approaches to establishing goals for climate change mitigation, including emissions concentrations in the atmosphere, emissions reduction goals or impact goals. The German Advisory Council on Global Change (WGBU 2009) and Garnaut Review (Garnaut 2008c), building on the work of Meinshausen et al. (2009), have adopted the budget approach described above whereby global mitigation is equated to the optimal depletion of a finite 'resource', in this case the resource being the 
'total ecologically tolerable quantity' of GHG emissions possible without triggering dangerous climate change (WGBU 2009: 21). Under this approach a global upper limit for emissions in the atmosphere is specified which is correlated with an overall budget for GHG emissions budgets with national budgets then assigned under the overall global budget. As we will see, this budget approach is particularly well suited to addressing intergenerational justice issues (see below 1.5).

\subsection{JUSTICE AND ETHICS ISSUES RAISED BY THE SCIENCE}

While the focus of this book is what justice requires of current generations towards future generations in relation to climate change, it is essential to assess this question within the broader questions of ethics and justice raised by the climate science sketched above. By 'ethics' I am referring to questions relating to whether action 'is right or wrong' (Mackie 1977: 9). In this book I use the term 'ethics' interchangeably with the term 'morality'. ${ }^{18}$ By 'justice', I am referring to questions that involve the distribution of 'a given measure or advantage (or benefit)' (Page 2006: 51), in other words, who gets how much of the pie, whether the 'pie' be natural resources, welfare or some other benefits. In the climate change context, the matrix of justice can refer to GHG emissions or benefits derived from emissions (discussed in Chapter 3 ).

The problem of climate change raises a number of justice issues. We have seen that by the middle of this century global GHG emissions will need to be reduced to zero (hereafter 'decarbonised'). If we think of GHG emissions as akin to a 'resource', this gives rise to the following distributional justice issues:

1. intergenerational ${ }^{19}$ - the level of mitigation burden to be borne by the current generation compared with future generations

2. intragenerational - justice within generations, that is, the level of mitigation to be borne by those living today in industrialised countries compared with those in developing countries, and between the poor and the rich within countries

3. international - the mitigation to be adopted by states vis-à-vis other states regardless of the distribution within states, including whether this be based on historical emission contributions, emissions since 1990, or other factors (Tremmel 2009: 5). 
It should be noted that the level at which justice issues are considered is vital. Thus categories '2. intragenerational' and ' 3 . international' differ in that the latter operates between states whereas the former operates between individuals and societies. The current international climate regime is state-based, with international justice principles that apply between countries embedded in the international legal structure (see 1.9 below). As we shall see, there are tensions between international justice and individual-level justice. For example, there are wealthy elites in developing countries who cause high GHG emissions, and poor people in industrialised countries, for example the poor in the US, who cause negligible emissions. But given the focus in this book on how obligations towards future generations should be reflected in international law, the focus is on categories (1) intergenerational justice and (3) international justice.

\subsection{INTRAGENERATIONAL AND HISTORIC JUSTICE}

It is important to understand that addressing the intergenerational justice issues, which are the focus of this book, necessarily involves issues of intragenerational justice, namely the distribution of mitigation burdens amongst people alive today. These distributional issues involve historic justice arguments, for example, the argument made by Brazil (and others) that industrialised countries whose emissions since the Industrial Revolution have caused the bulk of total emissions today have a correspondingly larger mitigation burden. ${ }^{20}$ Indeed, fossil fuel $\mathrm{CO}_{2}$ emissions from industrialised countries contributed cumulatively about 79 per cent of the global temperature increase due to long-lived $\mathrm{CO}_{2}$ emissions that result from fossil-fuel burning as of 1995 (Höhne and Blok 2005: 159). Recall that other GHGs (for example methane, nitrous oxide and halocarbons) also contribute to the overall warming and that their contribution is also significant to current warming. Consequently, a persuasive argument can be made that industrialised countries have overused what can be considered their entitlement to the atmospheric sink (see 3.5.4 below).

It is important to place these historic emissions in context. Some GHG emissions - such as methane - do remain in the atmosphere for a relatively short time. In contrast, $\mathrm{CO}_{2}$ remains in the atmosphere for hundreds of years, with 20 per cent of $\mathrm{CO}_{2}$ emissions still in the atmosphere after 650 years (Höhne and Blok 2005: 156). Nearly half of global cumulative GHG emissions have occurred since 1980. Moreover, the burgeoning growth of developing country emissions over the next decades will mean that pre-1990 emissions will represent a rapidly 
shrinking proportion of global cumulative emissions (Höhne et al. 2011) and thus by 2050 the fossil fuel $\mathrm{CO}_{2}$ from industrialised countries is estimated to contribute about 55 per cent to the projected global temperature increase under the IPCC SRES A2 scenario. If one considers all GHGs, industrialised countries are projected to contribute 45 per cent and developing countries 42 per cent by 2050 (Höhne and Blok 2005: 159). Under the same model, developing countries will have overtaken developed countries by 2050 in terms of radiative forcing - the impact on increased temperature on the surface of the earth - in relation to all gases, with industrialised countries 34 per cent and developing countries about 48 per cent. However, per capita emissions will remain much higher in industrialised countries. Even as of 1995, industrialised and developing countries already had equal contributions to current radiative forcing that drives the surface temperature changes. The projected relatively high emissions of industrialised countries reflect their earlier emissions and the longevity of $\mathrm{CO}_{2}$ in the atmosphere.

Even though most cumulative GHG emissions have occurred since 1980, historic emissions are important. For example, if one only counted emissions from 1900, one would ignore roughly 10 per cent of the cumulative effect of GHG emissions (Höhne and Blok 2005: 158). Taking into account historic emissions in mitigation burdens would only be possible if reasonably reliable data was available. The measuring of global historic $\mathrm{CO}_{2}$ emissions is not perfect but roughly comparable compared with the reliability of current measurement of emissions. However, measuring the contribution of individual countries is more problematic, particularly where those countries have an unusual emissions profile (Höhne et al. 2011: 8). Furthermore, GHG emissions data relating to methane and nitrous oxide have higher levels of uncertainty (Höhne et al. 2011: Annex 3) relative to fossil fuel $\mathrm{CO}_{2}$ emissions. Considerable uncertainty also remains in relation to measuring accurately historic emissions from forestry and land-use change (Höhne et al. 2011: $6)$.

The upshot of all of this is that historic GHG emissions should be appropriately taken into account in climate change mitigation and adaptation policies. But the shrinking proportion of global temperature rise attributable to historic emissions of industrialised countries suggests that care should be taken in terms of how this is done. Following Pickering and Barry (2012), I argue that historic emissions should be taken into account in funding mechanisms that assist developing countries in mitigation and adaptation. This is preferable to taking into account historic emissions in designing mitigation targets for individual countries that face the challenges outlined above. Further challenges in the latter 
include the difficulty of taking into account the fact that developing countries in the more recent period have been able to benefit from improved, more efficient technologies, which industrialised countries did not have access to during their development, although barriers to technology transfer to developing countries cannot be overlooked (Höhne and Blok 2005: 164).

Some experts argue that historic emissions of industrialised countries provide a strong rationale for allowing an overshoot in emissions by developing countries even beyond equal per capita shares (Garnaut 2008c: ch9, 9.5). However, allowing an overshoot can arguably jeopardise the possibility of reducing global GHG emissions rapidly enough in order to protect the interests of future generations (Macintosh 2010). ${ }^{21}$ Very quickly we can see that intragenerational justice issues impact on intergenerational justice and the two cannot be considered in isolation.

\subsection{INTERGENERATIONAL JUSTICE}

Intergenerational issues arise because a failure to make deep GHG emission cuts now will mean deeper and more economically disruptive reductions being required in the future, for example in 2030 when another generation is in positions of political power. See Figure 1.1.

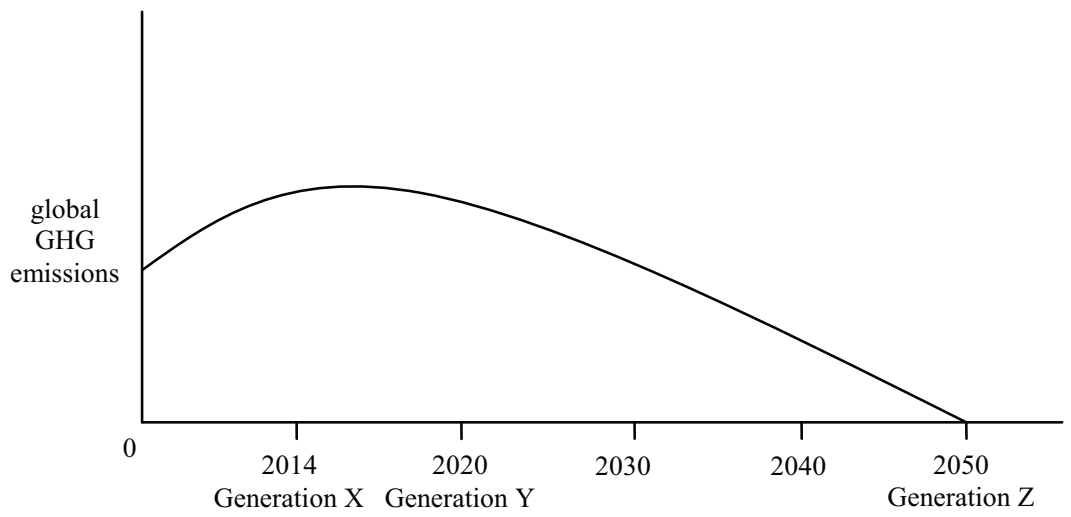

\section{Figure 1.1}

Another way of describing this is that we must devise a fairness or justice principle for dividing up a limited 'resource' consisting of GHG emissions (Shue 2011) - the area under the curve in Figure 1.1 - from now 
until roughly 2050, when the global economy must be decarbonised. Whatever distributional principle we adopt must operate within a context of interdependent generations, where for example action by Generation $\mathrm{X}$ (in 2014) in sharply reducing GHG emissions mostly benefits Generation $\mathrm{Z}$ (in 2050). The flipside of this is that where Generation X fails to act in reducing sharply GHG emissions, Generation $\mathrm{Z}$ will face higher costs in reducing emissions and greater risk of significant climate-change-related harm. In this model, the appearance of discrete generations and their labelling for convenience Generations ' $\mathrm{X}$ ' and ' $\mathrm{Z}$ ', is a simplification given the nature of overlapping generations (see below 1.5.1).

It is evident from the above that intergenerational justice issues arise in relation to climate change adaptation as well as mitigation. A failure by the current generation to strongly mitigate climate change will result in more harmful climate change impacts than would otherwise occur and increased adaptation costs to future generations.

Tremmel (2009: 19-20) points out that the term 'generation' is ambiguous and can refer to (1) people sharing the same family lineage, (2) a group of people with shared beliefs - societal generations, (3) a particular age group, that is, the young or middle-aged or elderly in a society alive at the same time or (4) everyone alive today. Tremmel distinguishes between the third and fourth categories, which he describes as 'chronological-temporal' and 'chronological-intertemporal', which are often blurred in other theories. In his theory he uses the term 'temporal justice between generations' for 'justice between young, middle-aged and older people alive today', whereas 'intertemporal generational justice' is defined as 'justice between people who lived in the past, people alive today and people who will live in the future' (Tremmel 2009: 22). In this book - unless stated otherwise - 'intergenerational justice' is used with the same meaning that Tremmel assigns to intertemporal generational justice. In this book 'future generations' will be defined (following Tremmel 2009: 24) as referring to generations where 'none of its members is alive at the time the reference is made' with all of its members born after the reference was made.

\subsubsection{Cascading Generations and Catastrophic Impacts}

Generations do not constitute a discrete group with one generation following the other in a neat chronology. Rather, generations are overlapping (Barry 1977: 271). This particular cascading quality of generations does not prevent one from making an assessment in very general terms about the respective interests of young people, people in positions of power or people to be born in the future at a particular point in time. 
Prior to the climate change issue becoming so acute, philosophers tended to argue that current generations had a particular responsibility to their immediate successor generation; however, it was considered difficult to extend such obligations well into the future beyond this up to, for example, 100 years. Climate change science has forced a change in these arguments for a number of reasons. ${ }^{22}$ Firstly, GHG emissions have a long lifespan, remaining in the atmosphere for long periods. A consequence of this is that a failure to sharply reduce GHG emissions now will have an impact on not just the next generation but succeeding generations after that. In addition, as we have seen, scientists are concerned that we risk reaching tipping points whereby catastrophic and irreversible changes in the climate system occur. Given the significant risk of this occurring, the current generation bears a particular responsibility.

\subsection{SUBSTANTIVE AND PROCEDURAL JUSTICE}

So far the discussion has been in terms of substantive justice. However, procedural justice is also important. The essence of procedural justice is strongly linked to a democratic principle that '[p]roblems that affect some group of persons ought to be decided by those persons, either directly or through their representatives' (Vanderheiden 2008: 90). Thus in the making of international treaties there must be meaningful participation of those affected by the treaty in the processes involved to ensure that their interests are taken into account. An important rationale for this principle of participation is that fair substantive policies are more likely to occur if the policy-making process itself is fair (Vanderheiden 2008: 62). This participatory principle is reflected in Principle 10 of the 1992 Rio Declaration, which states that '[e]nvironmental issues are best handled with the participation of all concerned citizens, at the relevant level'. The Aarhus Convention embodies this notion in a particularly strong form, linking an obligation on parties to guarantee 'public participation in decision-making' as a prerequisite for 'the protection of the right of every person of present and future generations to live in an environment adequate to his or her health and wellbeing' ${ }^{23}$

Procedural justice is particularly important in international law, as international treaties that are perceived to be fair in terms of the processes by which they are made are more likely to be complied with (Alford and Tierney 2012: 17). Given international law's lack of centralised enforcement mechanisms, procedural justice can help ensure legitimacy with better chances of compliance (Franck 1995: 26). 
This book seeks to identify criteria for attaining substantive justice for future generations in relation to climate change. But parallel to this, I argue that procedural justice should be strived for, as it is more likely to deliver substantive justice, measured through fulfilment of the proposed criteria. Given that future generations cannot directly take part in international law-making affecting their interests, 'rough' procedural justice can only ever be attained, based for example on indirect representation of future generations' interests by proxies. Such mechanisms are inherently difficult given the likelihood of current pressing concerns swamping the interests of future generations. Moreover, there is tension between substantive and procedural justice in the climate change context. More inclusive treaty-making processes may be procedurally fair but come at a price in terms of substantive justice, as the greater the number of parties involved in negotiations, the more difficult it is likely to be to reach agreement (Eckersley 2012: 25). This is problematic as reaching agreement quickly on mitigation action is crucial for future generations.

Chapter 7 briefly explores how intergenerational procedural justice can be incorporated in international law. This includes a discussion of potential international mechanisms with an explicit mandate to represent future generations' interests. Such mechanisms exist in some countries at the national level in the form of, for example, sustainable development commissions (Weston and Bach 2008). Indeed, during the negotiations leading to the Rio+20 Conference during 2012, a 'high level representative for sustainable development and future generations' was considered and strongly supported by the EU and many other Member States. ${ }^{24}$ However, it did not make its way into the outcome of that conference owing to concerns by some countries that such a mechanism would be used to monitor governments and that their national sovereignty was under threat. ${ }^{25}$

While procedural justice is important - and procedural mechanisms are worth exploring at the international level - a full evaluation of such proposals requires the input of social scientists and is beyond the scope of the normative focus of this book. This book, however, does provide a normative framework which could be valuable in considering procedural options being proposed.

\subsection{WHY DOES INTERGENERATIONAL JUSTICE MATTER FOR POLICY-MAKERS?}

As Garnaut points out, '[a]ction to mitigate climate change is premised on an obligation being owed to unborn generations as well as younger 
generations currently alive' (Garnaut 2008a: 5). So clarity on the nature and scope of such an obligation is an important precondition for effective policy-making in this area. Moreover, intergenerational justice is built into the current international legal framework and negotiating mandate for further developing this framework (1.10 and Chapter 4 below). In this sense, justice concerns are required to be considered by policy-makers (Soltau 2009: 3).

The focus in this book is on climate change mitigation, in other words action to reduce GHG emissions. Issues of how human societies adapt to climate change - so-called issues of adaptation - are also important but outside the scope of this book. The reason for limiting the book to mitigation issues is that mitigation is the 'first best' response to climate change. Delayed mitigation action entails passing on to the next generation greater costs in climate change adaptation. So intergenerational justice is involved in both climate change mitigation and climate change adaptation policy-making.

\subsection{ECONOMICS AND DISCOUNTING THE FUTURE}

Unmitigated climate change will involve substantial economic damage for future generations. The Stern Review concluded that unmitigated climate change would involve a decrease in the order of global GDP of between 5 per cent and 20 per cent (Stern 2007). ${ }^{26}$ A cost-benefit approach would therefore suggest that it is worthwhile to take strong climate change mitigation action now.

However, any economic cost-benefit analysis in relation to climate change mitigation must make an assumption about the value of damages in the future in dollar values today. Economists describe the method of converting future damages into contemporary dollar values as discounting (Splash 2002: 203). A key component of discounting is the notion of 'pure time preference', which refers to the idea that generally people prefer to have goods now rather than in the future and takes into account the risk that a person may not exist at some point in the future (Cline 2004: 5).

Many economists have used high discount rates to justify postponing strong mitigation action to address climate change (for example Nordhaus 2008). ${ }^{27}$ To illustrate, the cost of adapting to a $2^{\circ} \mathrm{C}$ warmer world by 2050 is estimated to be in the range of 70-100 billion USD per year by 2050 (World Bank 2010). Applying a discount rate of 6 per cent would value this today at only 17400 USD. Thus the value of future damage looks miniscule in today's values and pales in comparison to mitigation 
costs. Stern reflects the approach of ascribing equal value to all persons and, since his influential report, there has been a move away from high discount rates towards low discount rates in relation to climate change damages. ${ }^{28}$

High discount rates conflict with a core human rights principle according to which all persons born now and in the future have an equal right to life, health and subsistence (elaborated at 3.5.1 below). This principle entails that persons born now and in the future are of equal value. This book supports an interest-based theory of rights (Chapter 2), according to which there is no space for pure time preference as "[T]ime is not a morally relevant consideration' (Caney 2009: 169). The notion of 'pure time preference' entails in effect discriminating against people on the basis of when they happen to be born (Caney 2009: 169). Such discrimination violates a principle of 'impartiality' according to which political decisions should not penalise people on the basis of properties 'that lack any fundamental moral relevance' (Caney 2009: 168).

There are three additional problems with applying high discount rates to the cost-benefit analysis of mitigation measures. Firstly, the fact that individuals in their decisions relating to consumption give priority to immediate needs rather than long-term interests does not mean that public policy should follow such an approach (Splash 2002: 211). What individuals do in practice does not necessarily correspond to what they ought to do. Secondly, high discount rates, as we have seen, convert into weak climate change mitigation action, which leaves future generations threatened with a significant risk of catastrophic harm (Weitzman 2007: 707). So high discount rates entail ineffective policy prescriptions. Linked to this point is the assumption of continued economic growth, which may be questionable in the long term (Meadows et al. 2004) or even the short term (Carmody 2012: 69).

A related argument made by Lomborg (2007: ch24) and others is that expenditure on strong climate change mitigation now is misplaced because it involves ignoring the contemporary global poor and preferences future generations vis-à-vis current generations, which is unfair, as future generations will be wealthier than contemporaries.

However, the opportunity cost argument of Lomborg and others rests on an assumption that destruction of the global ecological system can be substituted by an increase in economic wealth. Put bluntly, if we pass onto the next generation a seriously impaired climate system, increased levels of wealth, education and technology will not be a satisfactory compensation for this radical change to a key earth system (Neumayer 1999: 34). This assumption of 'substitutability' is dubious as it ignores human beings' dependence on the global ecological system (Neumayer 
1999: 34), and in any event breaks down when the existential threat of climate change to the continued functioning of human civilisation is appreciated.

\subsection{WHY FOCUS ON INTERNATIONAL LAW?}

This leads to the question of why international law is important for addressing intergenerational justice aspects of climate change. Put differently, is a focus on international law in this book justified? An international treaty regime for addressing climate change is essential for a number of reasons. Firstly, without such a treaty regime, states which take action will bear costs not borne by their trading partners, which can lead states to avoid taking any action at all (Miller 2008: 121). Secondly, an international regime is essential in mobilising technology and funds to assist in both mitigation and adaptation efforts (Philibert 2004). To be most effective, technology transfer needs to be linked to binding targets under a climate change regime (Lawrence 2007: 195).

Reaching some broad agreement internationally on what constitutes both intergenerational justice and intragenerational justice is arguably a precondition for an effective international treaty addressing the climate change problem. Given the difficulty in enforcement mechanisms for international treaties, fairness is particularly important, as an agreement which is considered fair is more likely to be complied with (Miller 2008: 123). The US (and the previous Australian government under John Howard) argued that the Kyoto Protocol was unjust as it did not place any restrictions on emissions from developing countries. Even if such arguments were motivated by economic self-interest, there is no doubt that such arguments influenced the policy direction of these countries and viability of the treaty regime. Thus fairness can influence whether a treaty regime comes into being in the first place (Page 2006: 113).

The 'realist' school of international relations argues that concepts of justice are just window dressing, with power politics between nations pursuing their own sovereign national interests being determinative. However, this version of international relations glosses over the complex interaction between hard economic interest and justice principles involved in international negotiations (Scholtz 2009: 11-13). Thus a recent survey of responses of people involved in international negotiations 'concluded that equity was considered important' (Lange et al. 2007: 549-62). ${ }^{29}$ Moreover, to the extent that states act for selfish nationalist reasons, this does not mean that they should act in this way (Vanderheiden 2008: 94). Vanderheiden points out that 'realists' commit a 
so-called 'naturalistic fallacy' by deriving an ought from an is; 'even if all persons really are egoists at heart, this does not make it right or proper for nations to disregard ideals such as justice' (Vanderheiden 2008: 95).

\subsection{THE CURRENT UN CLIMATE REGIME AND NEGOTIATIONS}

We have seen that climate change science requires a virtual decarbonisation of the global economy by 2050, with GHG emissions reduced 10-40 per cent by 2020. How does the current international legal regime measure up to this imperative? The 1992 United Nations Framework Convention on Climate Change (UNFCCC) established a broad framework for cooperation and an overall goal of avoiding dangerous anthropogenic climate change (Article 2), but did not establish binding mitigation targets. The 1997 Kyoto Protocol to the UNFCCC did establish binding mitigation targets but only on industrialised countries and economies in transition (Eastern European countries). However, even if fully implemented, the Kyoto targets will only deliver a 5 per cent reduction in global emissions for industrialised countries and economies in transition (Eastern European countries) for the period 2008-12 (Sands and Peel 2012: 286).

In December 2009, at the Copenhagen conference of parties (COP) to the UNFCCC, governments agreed on a global objective of keeping global warming below $2^{\circ} \mathrm{C}$ (Copenhagen Accord para 2). This was accompanied by voluntary mitigation targets announced by many countries at this conference or in the period following. However, these efforts fall well short of what is required to reach a $2^{\circ} \mathrm{C}$ target (UNEP 2011). Moreover, to date, effective mitigation targets as part of the global climate regime remain elusive. The 17th COP to the Kyoto Protocol, held in Durban South Africa in 2011, made an in-principle decision to extend the Kyoto Protocol for another five to eight years (2013-2017/20). Parallel to this, the Durban conference agreed to launch under the so-called 'Durban platform' a negotiation process to develop a 'protocol, another legal instrument, or agreed outcome with legal force applicable to all parties' addressing the post-2020 period. ${ }^{30}$ But Durban failed to deliver an agreement on when global emissions should peak or any long-range global emissions reduction target. Moreover, the negotiating timetable - with a global agreement to be negotiated by 2015 and enter into force in 2020 - flies in the face of the urgency required by climate change science to deliver justice for future generations (Bodansky 2012a). 
At the meeting of parties to the Kyoto Protocol held in Doha in 2012, an amendment to the Kyoto Protocol was agreed enabling a second commitment period for the Protocol from 2013 to 2020. ${ }^{31}$ However, upon entry into force, the binding emission targets contained in the amendment will only apply to the EU, Australia, Switzerland and a few industrialised countries, totalling only 15 per cent of global GHG emissions. ${ }^{32}$ The US, Japan, Canada and Russia are not included.

It is important to note that while concrete mitigation action has been weak to date, the principle of intergenerational justice is reflected in Article 3(1) of the UNFCCC, which provides:

The Parties should protect the climate system for the benefit of present and future generations of human kind, on the basis of equity and in accordance with their common but differentiated responsibilities and respective capabilities. Accordingly, the developed countries Parties should take the lead in combatting climate change and the adverse effects thereof.

The current UNFCCC negotiations are based on the Durban platform but also the Bali action plan adopted in 2007. ${ }^{33}$ The latter includes the intergenerational principle described above as part of the principles in Article 3 of UNFCCC which comprise the relevant mandate. The implementation of these principles will continue to play a role in the negotiation of a post-2012 climate change regime, influencing in various ways the shape of those rules (see Chapter 4).

\subsection{CONCLUSION}

This chapter has had three broad themes: firstly, the intergenerational justice issues arising from climate change science; secondly, the intergenerational justice issues arising from 'discounting' by economists and related assumptions of increased wealth; and thirdly, the importance of international law as a vehicle for addressing intergenerational justice in the climate change context.

Intergenerational justice issues arise from the science of climate change owing to the persistence of $\mathrm{CO}_{2}$ in the atmosphere over long periods of time. Climate change science tells us that there is a high likelihood of future generations suffering increased mortality rates owing to climate-change-related impacts, some of which are irreversible (for example ocean acidification and species extinctions). Intergenerational justice issues arise as a failure to mitigate climate change by the current generation entails very likely significant harm to the interests of future generations. It also entails higher costs for future generations in terms of 
both mitigation and adaptation. Moreover, a failure by the current generation to take strong mitigation action entails a significant risk of catastrophic damage for future generations.

There is overwhelming support amongst atmospheric scientists that human beings are contributing to climate change by GHG emissions, while rates and regional distribution of impacts remain uncertain. But this uncertainty cannot provide a valid justification for delaying mitigation action for two reasons. Firstly, it misunderstands scientific method by incorrectly assuming that science can deliver absolute (100 per cent) certainty. Secondly, mitigation action is justified even if there is a range of harmful outcomes: precision in the level of harm is not a reasonable precondition for taking action when all the risk scenarios involve significant harm. The nature of the problem suggests that a precautionary approach is required: otherwise, action can end up being delayed until it is too late to be effective.

In response to these threats, scientists have concluded that the decarbonisation of the global economy is required by 2050 to have a better than even chance of staying below a $2^{\circ} \mathrm{C}$ global temperature rise - a widely accepted threshold for avoiding the worst of these impacts. A useful shorthand way to think of the mitigation challenge is to frame the issue as how to distribute fairly a cumulative emissions allocation of 1 trillion tonnes of $\mathrm{CO}_{2}$ (Shue 2011). This is an enormous challenge given global energy demand is currently continuing on an upward trajectory.

While the focus of this book is on intergenerational justice and international justice (between states), this cannot be considered in isolation from intragenerational justice. Thus arguments relating to whether historic emissions should be taken into account relate to both the role of industrialised countries' historic emissions in causing the climate change problem and the enormous disparities in current levels of wealth between developing and developed countries. Developing countries are likely to have an ever-increasing share of emissions, while per capita emissions of developing countries are likely to remain higher than industrialised countries for some time to come.

We will see that one of the most challenging issues in developing justifiable justice-based principles is how to balance the pressing needs of current generations - particularly the poor - with the needs of future generations. Indeed, economists have used high discount rates to justify delay in strong climate change mitigation action, often combining this with an argument that future generations will be wealthier than current generations, thus more capable of addressing climate change (for example Lomborg 2007). But these approaches make assumptions which 
conflict with notions of persons being born now and in the future being of equal worth. Furthermore, these approaches assume that permanent damage to global ecosystems can be replaced by increased economic wealth.

This raises the issue of whether procedural mechanisms can be devised to give future generations a greater voice in the law-making process in order to avoid permanent damage to global ecosystems upon which human beings depend. We observed that recent proposals to include such an international mechanism in the Rio+20 Conference ran into sovereignty concerns.

Indeed, state sovereignty remains at the heart of international law, leading some to suggest that international law is structurally incapable of addressing the intergenerational justice issues raised by climate change. But only a binding international treaty-level instrument is capable of addressing trade competitiveness concerns and delivering the necessary stability of commitments into the future, essential for intergenerational justice. The focus of this book on international law is therefore justified.

However, the current climate treaty regime only weakly reflects the imperatives of climate science and the need for action to ensure intergenerational justice. The Durban mandate is inadequate in its time frame, with the new global climate treaty to enter into force in 2020. The Kyoto Protocol has limited coverage (only 15 per cent of global emissions) and inadequate mitigation commitments.

Developing a global climate treaty under the Durban mandate depends on at least some broad agreement on the requirements of justice, both intra- and inter-generational. In the next chapter we turn to the latter.

\section{NOTES}

1. In this book the terms 'intergenerational justice' and 'intergenerational equity' will be given the same meaning unless it is clear from the context that the international law principle of 'intergenerational equity' is being referred to. The latter is addressed in Chapter 4.3.1 below.

2. See ABC News (2008), "Government encouraged to welcome "climate change refugees", ABC News, Mon 14 July, available at http:/www.abc.net.au/news/stories/ 2008/07/14/2302737.htm (accessed 19 December 2008). Inhabitants of the Carteret Islands in Papua New Guinea also face the prospect of relocation.

3. See Stern (2007), Garnaut (2008c: ch9).

4. Neither the United Nations Framework Convention on Climate Change nor the Kyoto Protocol defines the terms 'developed' or 'developing' countries. It is clear, however, that 'developed countries' are equated with UNFCCC Annex 1 parties and 'developing countries' with non-Annex 1 parties. The terminology used in this book follows this understanding while recognising this is problematic as some 'developing countries' so defined include South Korea, Mexico and Chile, who are members of 
the OECD (D. Bodansky, 'W[h]ither the Kyoto protocol, Durban and beyond' August 2011 Harvard Project on Climate Agreements http://belfercenter.ksg.harvard.edu/ files/Bodansky_Viewpoint-Final.pdf. Accessed 13 September 2013).

On occasion I use the term 'industrialised' synonymously with 'developed'. See 7.4 below, which discusses how the classification of countries under the current UNFCCC may need to be reformed.

5. But developing countries have nevertheless also emphasised obligations towards future generations in their rhetoric; see Chapter 6 below.

6. Scholtz (2009: 167) uses the word 'pragmatism' but I prefer the term 'feasibility' as it captures the notion of whether a climate regime is feasible in addressing the environmental issue at stake.

7. There is considerable literature on sustainable development in international law (see 4.3.1 below), but very little material on intergenerational equity as a freestanding concept in international law. The notable exception is the path-finding book by Edith Brown Weiss, In Fairness to Future Generations: International Law: Common Patrimony, and Intergenerational Equity (The United Nations University). See also E. Agius and S. Busuttil (eds), Future Generations and International Law (Earthscan 1998).

8. The fifth IPCC Assessment Report Working Group 1 The Physical Science Basis is due to be released in September 2013, Working Group 2 on Impacts, Adaptation and Vulnerability, March 2014 and Working Group 3 on Mitigation, April 2014 (www.ip cc.ch accessed 27 March 2013).

9. Other surveys include Oreskes, 'Beyond the Ivory Tower' (2004), and Doran and Kendell-Zimmerman, 'Examining the Scientific Consensus on Climate Change' (2009).

10. In Allison et al. (2009: 34).

11. Some have suggested that the sheer scale of human-generated changes to the biosphere means that a new geological era is beginning and that 'the relatively stable geological era which prevailed since the previous ice age - the Holocene, no longer applied'. The term 'Anthropocene' has been used to describe this transformation (Simon Dalby, 'Biopolitics and Climate Security in the Anthropocene', 49 (2013) Geoforum 184). See also references in Louis Koetze, 'Reimagining Global Environmental Law and Governance in the Anthropocene' 27 September 2012, Scientific Contributions, Series H: Inaugural Address: 252 http://dspace.nwu.ac.za/handle/ 10394/8575 accessed 2 September 2013, 3.

12. This scenario assumes that the activity producing the toxic material can be carried out in a manner that does not produce the toxic material, that is, there are viable less harmful options. How this assumption plays out in relation to climate change is discussed below at 3.5.3.

13. In: Gardiner et al. (2010: 81).

14. Decision 2/CP15, Report of the Conference of the Parties on its Fifteenth Session, Copenhagen, 7-19 December 2009, FCCC/CP/2009/11/Add.1 (30 March 2010) (Copenhagen Accord) para 2.

15. Referred to in Garnaut (2011: 38).

16. See http://trillionthton.org/. Accessed 3 October 2012.

17. Thus the WGBU proposes a global budget of 750 gigatonnes of $\mathrm{CO}_{2}$ from fossil fuel emissions for the period 2010-2050 (WGBU 2009: 2).

18. Grayling points out that 'ethics' is a broader concept than 'morality' involving how a person lives their life, whereas morality is confined chiefly to interpersonal relationships. See A.C. Grayling, The Choice of Hercules, Pleasure, Duty and the Good Life in the 21st Century (Phoenix 2007: 71).

19. See 1.5 below for a definition of future 'generations'. 
20. For a recent version of the Brazilian proposal, see 'Ideas and proposals on the elements contained in paragraph 1 of the Bali action plans' submissions from parties' Part I (19 May 2009) FCCC/AWGLCA/2009/MISC.4 (Part I) 54-5.

21. Macintosh (2010) suggests that if developed countries adopt a combined target of less than 20 per cent reduction by 2020 against 1990 levels, this would mean that global carbon emissions would have to be reduced post- 2030 by between 5 per cent and 10 per cent per year to keep global warming below $2^{\circ} \mathrm{C}$. He suggests that the chances of staying below the $2^{\circ} \mathrm{C}$ target are very low without stronger mitigation targets being adopted. See also UNEP (2011).

22. This reflects the fact that since the nuclear age human beings have for the first time in history the capacity to irreversibly damage the future of the planet by use of technologies (Tremmel 2009: 1).

23. Principle 1 Aarhus Convention.

24. See proposal contained in UN document: 'The Future we Want', United Nations, Rio+20, United Nations conference on sustainable development, 10 January, 2012, page 10, para 57. This is discussed below at 7.6.1.

25. Anonymous source on file with the author.

26. See discussion of Stern's discount rate in Weitzman (2007: 708).

27. Skott and Davis (2012: 1) state that 'Nordhaus (2008) and most other studies ... use a "descriptive" approach in which the welfare function of the representative agent has to be calculated to fit empirical observations.' This is contrasted with Stern's 'proscriptive' approach. The proscriptive/descriptive terminology is used by Arrow et al. (IPCC 1996: chapter 4).

28. Nicholas Stern applied a pure time preference of 0.1 per cent to take into account the possibility that the human race is extinguished, for example by a nuclear conflagration which equates to a 90 per cent probability of humanity surviving a 100-year period. He applied an elasticity of marginal consumption rate of 1 and a per capita growth rate of consumption of 1.3 per cent. These figures combined to give Stern a total discount rate of 1.4 per cent (Stern 2007: 663). See discussion of Stern's discount rate in Weitzman (2007: 708).

29. In Kverndokk and Rose (2008: 38).

30. Decision 1/CP.17 para 2, 'Report of the Conference of the Parties on its 17th session, held in Durban from 28 November to 11 December 2011' UN Doc. FCCC/CP/2011/ 9/Add.1, 15 March 2012.

31. FCCC/KP/CMP/2012L.9 (8 December 2012).

32. R. Harrabin (8 December 2012) 'UN climate talks extended Kyoto Protocol, promise compensation', BBC News, www.bbc.co.uk/news/science-environment/20653018 accessed 14 February 2013.

33. Bali Action Plan, Decision 1/CP.13 adopted by the UNFCCC 13th Conference of Parties, 3-15 December 2007, FCCC/CP/2007/6/ Add. 1 (14 March 2008) http:// unfccc.int/resource/docs/2007/cop13/eng/06a01.pdf accessed 18 September 2013. 